\title{
Analysis of Lightning-Induced Voltages on Overhead Lines Using a 2-D FDTD Method and Agrawal Coupling Model
}

\author{
He-Ming Ren, Bi-Hua Zhou, Member, IEEE, Vladimir A. Rakov, Fellow, IEEE, Li-Hua Shi, Member, IEEE, \\ Cheng Gao, Member, IEEE, and Jian-Hua Yang
}

\begin{abstract}
In this paper, the lightning-generated electromagnetic fields over lossy ground produced by lightning strikes either to flat ground or to a tall tower are calculated using the 2-D finitedifference time-domain (FDTD) method. The resultant horizontal and vertical electric fields are used as forcing functions in the discretized Agrawal electromagnetic coupling equations for the calculation of induced voltages on overhead horizontal conductors without employing the Cooray-Rubinstein formula. Comparison of the results with those obtained using the 3-D FDTD method and with experimental data found in the literature is used to test the validity of the examined method. The approach employed here generally provides sufficient accuracy while allowing significant reduction in computation time and storage requirements as compared to the 3-D FDTD method. From the analysis carried out in this paper, induced voltages appear to be strongly dependent on ground conductivity, somewhat influenced by return-stroke speed, and essentially independent of return-stroke model [transmission-line (TL), modified transmission line with linear current decay with height (MTLL), or modified transmission line with exponential current decay with height (MTLE)].
\end{abstract}

Index Terms-Electromagnetic coupling model, finite-difference time-domain (FDTD) method, lightning electromagnetic pulse (LEMP), lightning-induced voltage.

\section{NOMENCLATURE}

$\begin{array}{ll}H & \text { Length of the lightning return-stroke channel. } \\ h & \text { Height of the strike object. } \\ d & \begin{array}{l}\text { Shortest distance between the overhead line } \\ \text { and the lightning return-stroke channel. }\end{array} \\ I(0, t) & \begin{array}{l}\text { Lightning channel base current. } \\ \text { Current in the strike object and lightning } \\ I(z, t)\end{array} \\ v & \begin{array}{l}\text { return-stroke channel at height } z . \\ \text { Return-stroke speed. }\end{array} \\ c & \text { Speed of light in free space. }\end{array}$

Manuscript received June 14, 2007; revised October 9, 2007 and January 4, 2008. This work was supported in part by the Chinese National Natural Science Foundation under Grant 50237040 and Grant 60471013 , and in part by the National Science Foundation under Grant ATM-0346164.

H.-M. Ren and J.-H. Yang are with the College of Optoelectric Science and Engineering, National University of Defense Technology, Changsha 410073, China (e-mail: rhm0412@126.com).

B.-H. Zhou, L.-H. Shi, and C. Gao are with the Nanjing Engineering Institute, Nanjing 210007, China.

V. A. Rakov is with the Department of Electrical and Computer Engineering, University of Florida, Gainesville, FL 32611 USA (e-mail: rakov@ece.ufl.edu). Digital Object Identifier 10.1109/TEMC.2008.926910

\begin{tabular}{|c|c|}
\hline$\rho_{\mathrm{gr}}$ & $\begin{array}{l}\text { Current reflection coefficient at the channel } \\
\text { base (ground) in the case of strikes to flat } \\
\text { ground. }\end{array}$ \\
\hline$\rho_{\text {top }}$ & $\begin{array}{l}\text { Current reflection coefficient at the top of } \\
\text { the strike object for upward propagating } \\
\text { waves. }\end{array}$ \\
\hline$\rho_{\text {bot }}$ & $\begin{array}{l}\text { Current reflection coefficient at the bottom of } \\
\text { the strike object. }\end{array}$ \\
\hline$\Delta z$ & $\begin{array}{l}\text { Spatial discretization interval along the } z \text {-axis } \\
\text { in the } 2 \text {-D FDTD integration scheme. }\end{array}$ \\
\hline$\Delta r$ & $\begin{array}{l}\text { Spatial discretization interval in the radial di- } \\
\text { rection in the 2-D FDTD integration scheme. }\end{array}$ \\
\hline$\Delta x$ & $\begin{array}{l}\text { Spatial discretization interval along the } x \text { - } \\
\text { axis in the discretization of Agrawal coupling } \\
\text { equations. }\end{array}$ \\
\hline$\Delta t$ & Time discretization interval. \\
\hline$E_{r}$ & $\begin{array}{l}\text { Horizontal component of the lightning- } \\
\text { generated electric field. }\end{array}$ \\
\hline$E_{z}$ & $\begin{array}{l}\text { Vertical component of the lightning- } \\
\text { generated electric field. }\end{array}$ \\
\hline$H_{\varphi}$ & $\begin{array}{l}\text { Horizontal component of the lightning- } \\
\text { generated magnetic field. }\end{array}$ \\
\hline$\left[v_{p}^{s}(x, t)\right]$ & Matrix of the scattered voltage vector. \\
\hline$\left[v_{p}(x, t)\right]$ & Matrix of the total voltage vector. \\
\hline$\left[v_{p}^{e}(x, t)\right]$ & $\begin{array}{l}\text { Matrix of the exciting (or incident) voltage } \\
\text { vector. }\end{array}$ \\
\hline$\left[i_{p}(x, t)\right]$ & $\begin{array}{l}\text { Matrix of the current vector along the over- } \\
\text { head line. }\end{array}$ \\
\hline$h_{p}$ & Height of conductor $p$ above ground. \\
\hline$\left[E_{x}^{e}\left(x, h_{p}, t\right)\right]$ & $\begin{array}{l}\text { Matrix of the horizontal component of the ex- } \\
\text { citing (or incident) electric field vector along } \\
\text { the } x \text {-axis at the } p \text { th conductor's height } h_{p} \text {. }\end{array}$ \\
\hline$E_{z}^{e}(x, 0, t)$ & $\begin{array}{l}\text { Vector of the vertical component of the inci- } \\
\text { dent electric field. }\end{array}$ \\
\hline$\left[L_{p q}^{\prime}\right]$ & Per-unit-length inductance matrix of the line. \\
\hline$\left[C_{p q}^{\prime}\right]$ & Per-unit-length capacitance matrix of the line. \\
\hline & Transient ground resistance matrix. \\
\hline$\left[R_{0}\right],\left[R_{L}\right]$ & $\begin{array}{l}\text { Matrices of resistances at the line } \\
\text { terminations. }\end{array}$ \\
\hline$\sigma$ & Conductivity of the medium. \\
\hline$\varepsilon$ & Permittivity of the medium. \\
\hline$\mu_{0}$ & Permeability of free space. \\
\hline$\varepsilon_{0}$ & Permittivity of free space. \\
\hline$\sigma_{g}$ & Conductivity of the earth. \\
\hline$\varepsilon_{r g}$ & Relative permittivity of the earth. \\
\hline
\end{tabular}




\author{
$R_{g} \quad$ Grounding resistance of line's neutral \\ conductor. \\ $\lambda \quad$ Current decay height constant.
}

\section{INTRODUCTION}

$\mathbf{L}$ IGHTNING is a major natural source of electromagnetic radiation that interferes with modern electric and communication systems. The evaluation of lightning-induced voltages typically involves the calculation of the lightning return-stroke electromagnetic field variation along the considered line and a field-to-transmission line coupling model [1]-[5] that describes the interaction of lightning electromagnetic fields with that line.

The ground conductivity plays a role in the evaluation of both lightning-radiated electromagnetic fields and the line parameters. The line parameters include the longitudinal ground impedance and the transverse ground admittance, which are both frequency-dependent. The latter can generally be neglected for typical overhead lines, due to its small contribution to the overall transverse admittance of the line [6]. Rachidi et al. [7] showed that for lines whose length does not exceed a certain "critical" value (typically $2 \mathrm{~km}$ ) and for the strike point equidistant from the line terminations, the surge propagation along the line is not appreciably affected by the ground finite conductivity, and therefore, the ground impedance can also be neglected. In general, however, the ground impedance should be taken into account. In this study, we will neglect the ground impedance and show that this assumption is apparently justified for all the configurations considered in Section III.

For the calculation of lightning-radiated fields over finitely conducting ground, the inclusion of lossy ground effects is necessary, especially for the calculation of the horizontal electric field. Many authors have resorted to the so-called CoorayRubinstein approximate formula [8]-[10]. Limits of validity of this formula relative to the exact solution were examined by Wait [11]. It appears to be inapplicable for distances closer than about $200 \mathrm{~m}$ and for very-low-conductivity ground (e.g., $0.1 \mathrm{mS} / \mathrm{m}$ ). It is worth noting that the Cooray-Rubinstein formula can be derived from a more general equation presented by Shoory et al. [12].

Hoidalen et al. [13] have used a new analytical formulation to calculate the lightning-induced voltages. Its accuracy is believed to be reasonable when the overhead line is located $100 \mathrm{~m}$ to $10 \mathrm{~km}$ from the lightning channel, the ground conductivity is higher than $0.001 \mathrm{~S} / \mathrm{m}$, the length of the line is shorter than $1 \mathrm{~km}$, and for the first few microseconds, when the maximum induced voltage often occurs.

Baba and Rakov [14] calculated lightning-induced voltages for lightning strikes to flat ground and to a tall grounded object using the TL model extended to include a tall strike object without invoking any electromagnetic coupling model [15], [16]. Their calculations were carried out using the 3-D finitedifference time-domain (FDTD) method, and induced voltages on a horizontal conductor were calculated by directly integrating the vertical electric field from the ground surface to the wire height.

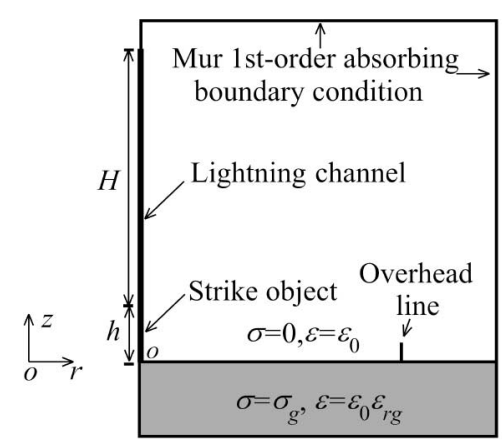

(a)

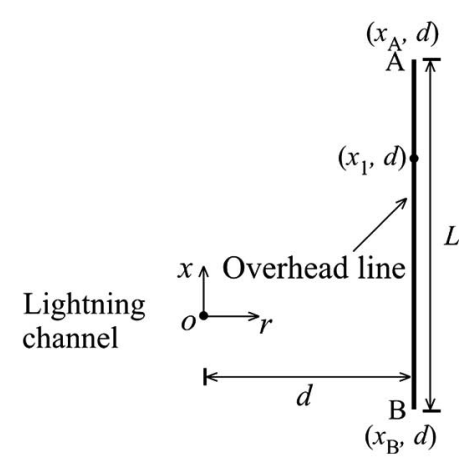

(b)

Fig. 1. Configuration to be analyzed using the 2-D FDTD method. (a) Side view. (b) Plan view.

In this paper, we employ a 2-D FDTD method for calculation of lightning-generated electromagnetic fields above lossy ground. Induced voltages are found using the Agrawal electromagnetic coupling model that describes the interaction of these fields with overhead lines. Computed results are compared with those obtained using a more rigorous 3-D FDTD method and with experimental data. We show that our approach provides sufficient accuracy while being more computationally efficient than that based on the 3-D FDTD method.

\section{Methodology}

\section{A. Calculation of the Horizontal and Vertical Electric Fields}

The configuration of the system is shown in Fig. 1. The length of the lightning return-stroke channel is $H$. It is assumed to be straight and vertical. The channel base current is $I(0, t)$ and the return-stroke propagation speed is $v$.

The current distribution $I(z, t)$ along the lightning channel for the case of lightning strikes to flat ground for three TL-type models is given by the following

Transmission line model [17]:

$$
I(z, t)=I\left(0, t-\frac{z}{v}\right) .
$$

Modified transmission line model with linear current decay with height (MTLL model) [18]:

$$
I(z, t)=\left(1-\frac{z}{H}\right) I\left(0, t-\frac{z}{v}\right) .
$$


Modified TL model with exponential current decay with height (MTLE model) [19]:

$$
I(z, t)=e^{-z / \lambda} I\left(0, t-\frac{z}{v}\right) .
$$

The current distribution $I(z, t)$ along the lightning channel based on the TL model for the case of lightning strikes to a tall grounded object of height $h$ is given by [15], [16]

$$
\begin{aligned}
& I(z, t)= \frac{1-\rho_{\mathrm{top}}}{2} \\
& \times \sum_{k=0}^{\infty}\left[\begin{array}{c}
\rho_{\mathrm{bot}}^{k} \rho_{\mathrm{top}}^{k} I\left(h, t-\frac{h-z}{c}-\frac{2 k h}{c}\right) \\
+\rho_{\mathrm{bot}}^{k+1} \rho_{\mathrm{top}}^{k} I\left(h, t-\frac{h+z}{c}-\frac{2 k h}{c}\right) \\
0 \leq z \leq h \text { (along the strike object) }
\end{array}\right.
\end{aligned}
$$

$$
\begin{aligned}
& I(z, t)=\frac{1-\rho_{\text {top }}}{2} \\
& \times {\left[\begin{array}{l}
I\left(h, t-\frac{z-h}{v}\right) \\
+\sum_{k=1}^{\infty} \rho_{\text {bot }}^{k} \rho_{\text {top }}^{k-1}\left(1+\rho_{\text {top }}\right) I\left(h, t-\frac{z-h}{v}-\frac{2 k h}{c}\right)
\end{array}\right] } \\
& h \leq z \text { (along the lightning channel) }
\end{aligned}
$$

where $\rho_{\text {bot }}$ and $\rho_{\text {top }}$ are the current reflection coefficients at the bottom of the strike object and at the top of the object, respectively, and $k$ is an index representing the successive multiple reflections occurring at the two ends of the strike object.

The 2-D FDTD meshes are illustrated in Fig. 2, and the finitedifference equations for the horizontal electric field $E_{r}$, vertical electric field $E_{z}$, and horizontal magnetic fiel, $H_{\varphi}$ can be written as in (6)-(8), shown at the bottom of the page [20]

In this paper, we employ the first-order Mur absorbing boundary conditions [21] in order to simulate unbounded space.

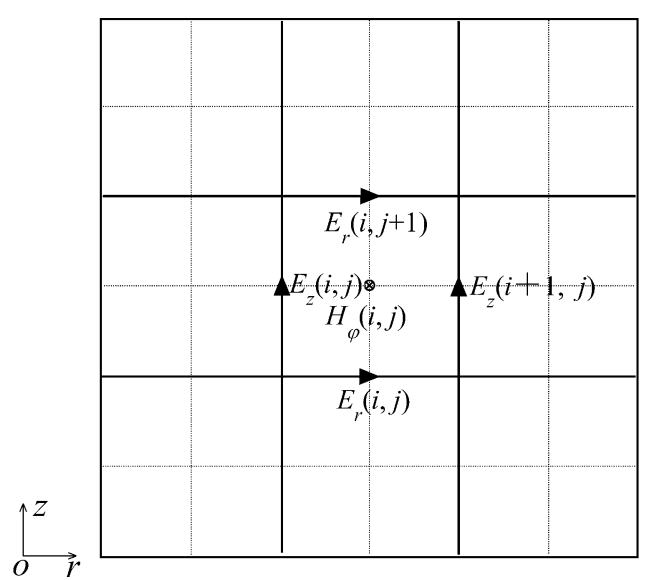

Fig. 2. Two-dimensional FDTD meshes in cylindrical coordinates.

\section{B. Coupling of Electromagnetic Field to Overhead Line}

For the case of a multiconductor line, the Agrawal coupling model [4] can be written in the time domain as

$$
\begin{aligned}
\frac{\partial}{\partial x}\left[v_{p}^{s}(x, t)\right]+\left[L_{p q}^{\prime}\right] \frac{\partial}{\partial t}\left[i_{p}(x, t)\right] & +\left[\xi_{p q}^{\prime}\right] \otimes \frac{\partial}{\partial x}\left[i_{p}(x, t)\right] \\
& =\left[E_{x}^{e}\left(x, h_{p}, t\right)\right] \\
\frac{\partial}{\partial x}\left[i_{p}(x, t)\right]+\left[C_{p q}^{\prime}\right] \frac{\partial}{\partial t}\left[v_{p}^{s}(x, t)\right] & =0
\end{aligned}
$$

where $\left[v_{p}^{s}(x, t)\right]$ is related to the total voltage $\left[v_{p}(x, t)\right]$ by the following expression:

$$
\left[v_{p}^{s}(x, t)\right]=\left[v_{p}(x, t)\right]-\left[v_{p}^{e}(x, t)\right]
$$

where $\left[v_{p}^{e}(x, t)\right]=-\int_{0}^{h_{p}} E_{z}^{e}(x, z, t) \mathrm{d} z \approx-h_{p} E_{z}^{e}(x, 0, t)$ and " $\otimes$ " denotes the convolution integral.

The boundary conditions, for the case of resistive terminations, are

$$
\begin{aligned}
{\left[v_{p}^{s}\left(x_{0}, t\right)\right] } & =-\left[R_{0}\right]\left[i_{p}\left(x_{0}, t\right)\right]+\left[h_{p}\right] E_{z}^{e}\left(x_{0}, 0, t\right) \\
{\left[v_{p}^{s}\left(x_{L}, t\right)\right] } & =\left[R_{L}\right]\left[i_{p}\left(x_{L}, t\right)\right]+\left[h_{p}\right] E_{z}^{e}\left(x_{L}, 0, t\right)
\end{aligned}
$$

where $\left[R_{0}\right]$ and $\left[R_{L}\right]$ are the matrices of the line termination resistances.

$$
\begin{aligned}
E_{r}^{n+1}\left(i+\frac{1}{2}, j\right)= & \frac{2 \varepsilon-\sigma \Delta t}{2 \varepsilon+\sigma \Delta t} E_{r}^{n}\left(i+\frac{1}{2}, j\right)-\frac{2 \Delta t}{(2 \varepsilon+\sigma \Delta t) \Delta z}\left[H_{\varphi}^{n+(1 / 2)}\left(i+\frac{1}{2}, j+\frac{1}{2}\right)-H_{\varphi}^{n+(1 / 2)}\left(i-\frac{1}{2}, j+\frac{1}{2}\right)\right] \\
E_{z}^{n+1}\left(i, j+\frac{1}{2}\right)= & \frac{2 \varepsilon-\sigma \Delta t}{2 \varepsilon+\sigma \Delta t} E_{z}^{n}\left(i, j+\frac{1}{2}\right)+\frac{2 \Delta t}{(2 \varepsilon+\sigma \Delta t) r_{i} \Delta r}\left[r_{i+(1 / 2)} H_{\varphi}^{n+(1 / 2)}\left(i+\frac{1}{2}, j+\frac{1}{2}\right)\right. \\
& \left.-r_{i-(1 / 2)} H_{\varphi}^{n+(1 / 2)}\left(i-\frac{1}{2}, j+\frac{1}{2}\right)\right] \\
H_{\varphi}^{n+1 / 2}\left(i+\frac{1}{2}, j+\frac{1}{2}\right)= & H_{\varphi}^{n-1 / 2}\left(i+\frac{1}{2}, j+\frac{1}{2}\right)+\frac{\Delta t}{\mu_{0} \Delta r}\left[E_{z}^{n}\left(i+1, j+\frac{1}{2}\right)-E_{z}^{n}\left(i, j+\frac{1}{2}\right)\right] \\
& -\frac{\Delta t}{\mu_{0} \Delta z}\left[E_{r}^{n}\left(i+\frac{1}{2}, j+1\right)-E_{r}^{n}\left(i+\frac{1}{2}, j\right)\right]
\end{aligned}
$$




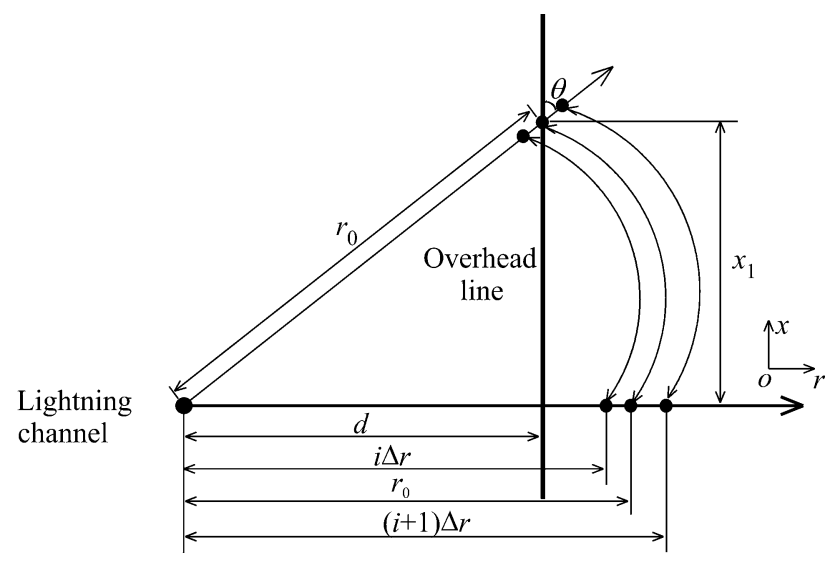

Fig. 3. Relative location of lightning channel and overhead line.

The electric field $E_{x}$ along the line at distance $r_{0}$ from the lightning return stroke channel was calculated using the 2-D FDTD method for configuration shown in Fig. 1. An interpolation technique had to be adopted in case the distance $r_{0}$ does not exactly correspond to the FDTD grid point. For the geometry shown in Fig. 3, with $r_{0}=\sqrt{d^{2}+x_{1}^{2}}$, we set $i=\operatorname{int}\left(r_{0} / \Delta r\right)$, so that the horizontal electric field in the radial direction from the lightning channel is

$E_{r}\left(r_{0}\right)=\left(1-\frac{d-i \Delta r}{\Delta r}\right) E_{r}(i \Delta r)+\frac{d-i \Delta r}{\Delta r} E_{r}((i+1) \Delta r)$

and the horizontal electric field along the overhead line is

$$
E_{x}(i)=E_{r}\left(r_{0}\right) \cos \theta=E_{r}\left(r_{0}\right) \frac{x_{1}}{r_{0}}
$$

where $E_{x}(i)$ is the excitation term in the discretized electromagnetic coupling equations.

Using the point-centered finite-difference technique and neglecting the convolution integral, we can discretize (9), (10), (12), and (13) and solve them directly in the time domain

$$
\begin{aligned}
& {\left[v_{p}^{s}(i \Delta x,(n+1) \Delta t)\right]=\left[v_{p}^{s}(i \Delta x, n \Delta t)\right]} \\
& \quad+\frac{\left[C_{p q}^{\prime}\right]^{-1}}{\Delta t} \frac{\left[i_{p}((i-1) \Delta x, n \Delta t)\right]-\left[i_{p}(i \Delta x, n \Delta t)\right]}{\Delta x}, \\
& i=2,3, \ldots, n \max -1 \\
& {\left[i_{p}(i \Delta x,(n+1) \Delta t)\right]=\left[i_{p}(i \Delta x, n \Delta t)\right]} \\
& \quad-\frac{\left[L_{p q}^{\prime}\right]^{-1}}{\Delta t}\left[\frac{\left[v_{p}^{s}((i+1) \Delta x, n \Delta t)\right]-\left[v_{p}^{s}(i \Delta x, n \Delta t)\right]}{\Delta x}\right. \\
& \left.\quad-\frac{\left[E_{x}^{e}\left(i \Delta x, h_{p},(n+1) \Delta t\right)\right]+\left[E_{x}^{e}\left(i \Delta x, h_{p}, n \Delta t\right)\right]}{2}\right] \\
& {\left[v_{p}^{s}(1,(n+1) \Delta t)\right]} \\
& \quad=-\left[R_{0}\right]\left[i_{p}(1,(n+1) \Delta t)\right]+\left[h_{p}\right] E_{z}^{e}(1,0,(n+1) \Delta t) \\
& {\left[v_{p}^{s}(n \max ,(n+1) \Delta t)\right]} \\
& \quad=\left[R_{L}\right]\left[i_{p}(n \max ,(n+1) \Delta t)\right]+\left[h_{p}\right] E_{z}^{e}(n \max ,(n+1) \Delta t) .
\end{aligned}
$$

The horizontal electric field $E_{x}$ in (17) is computed using the 2-D FDTD method; it can be directly inserted into the finite difference equations to obtain the induced voltages and currents at any position along the line.

The spatial discretization interval $\Delta x$ in (16) and (17) equals the spatial discretization interval $\Delta r$ in the calculation of electromagnetic fields and the time discretization interval $\Delta t \leq \Delta x / 2 c$, which satisfies the Courant stability condition $\Delta t \leq \Delta x / c$.

\section{ANALYSIS AND DISCUSSION}

\section{A. Lightning Strikes to Flat Ground}

1) Comparison With Voltages Computed Using the 3-D FDTD Method: Baba and Rakov [14] computed induced voltages due to lightning strikes to both flat ground and tall grounded object using the 3-D FDTD method without invoking any electromagnetic coupling model. In their simulation, a 1200-m-long horizontal wire had a radius of $5 \mathrm{~mm}$ and was located $10 \mathrm{~m}$ above the ground. Each end of the horizontal wire was terminated with a $498-\Omega$ matching resistor. The strike point was equidistant from the line terminations. The conductivity and relative permittivity of the earth for both flat ground case and tall grounded object case were set to $\sigma_{g}=0.01 \mathrm{~S} / \mathrm{m}$ and $\varepsilon_{r g}=10$. The return-stroke speed was $v=c / 3$. The current waveform used in our simulation was the one proposed by Nucci et al. [22] and adopted by Baba and Rakov [14]. Its peak is $11 \mathrm{kA}$ and peak derivative is $105 \mathrm{kA} / \mu \mathrm{s}$.

In this section, we compare the results obtained using the 2-D FDTD method with those calculated using the 3-D FDTD method for flat ground conditions. The comparison for lightning strikes to tall tower conditions will be presented in Section III-B1.

From Fig. 4(a) and (b), one can see that induced voltages calculated using the 2-D FDTD method and Agrawal coupling model agree fairly well with those calculated using the 3-D FDTD method.

2) Comparison With Experimental Data: In this section, we compare lightning-induced voltages calculated using the 2-D FDTD method and Agrawal coupling model with those measured by Barker et al. [23]. In Barker et al.'s experiment, a rocket-triggered lightning channel was at a distance of $145 \mathrm{~m}$ from the center of a two-conductor overhead line, as shown in Fig. 5. The line was $682 \mathrm{~m}$ long, and the two conductors were vertically stacked with separation between them being $1.8 \mathrm{~m}$. The line was supported by 15 wooden poles spaced about 49 $\mathrm{m}$ apart. The upper conductor was placed above the ground at a height of $7.5 \mathrm{~m}$ and simulated the phase conductor. It was connected to the lower conductor by $455-\Omega$ resistors at the termination poles. The lower conductor, which simulated the neutral, was grounded at both ends and at pole 9 (the grounding at pole 9 was treated in our model as a resistive load). The grounding resistance values were between 30 and $75 \Omega$. Barker et al. have measured channel-base currents, corresponding fields, and induced voltages at poles 1,9 , and 15 .

We approximated the return-stroke current measured by Barker et al. for the only stroke in Flash 93-05 by the sum 


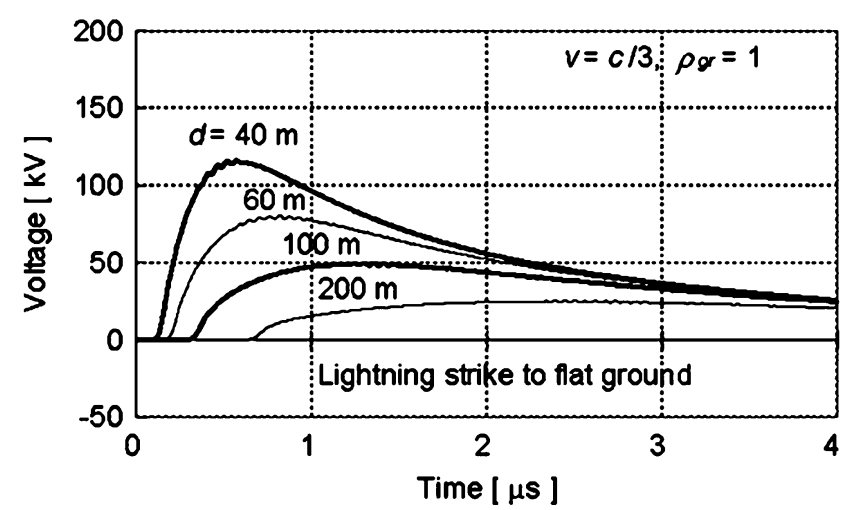

(a)

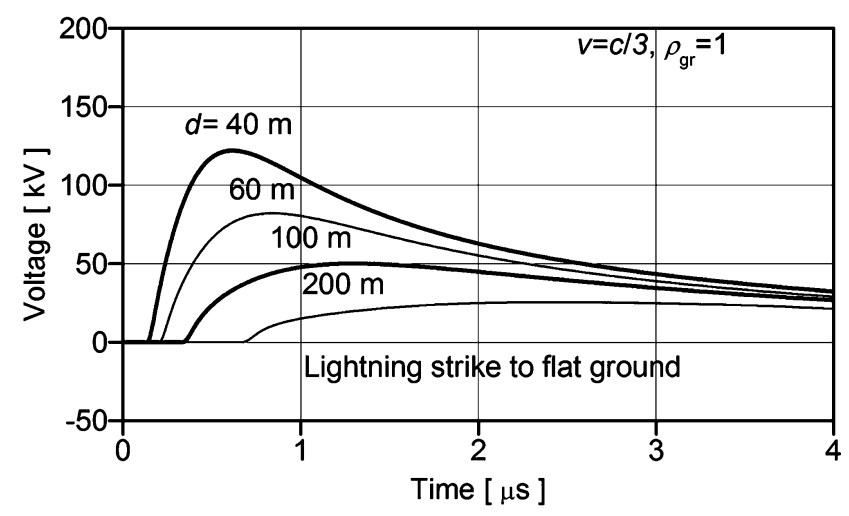

(b)

Fig. 4. (a) Lightning-induced voltages at the center point of the horizontal wire at distances $d=40,60,100$, and $200 \mathrm{~m}$ from the lightning channel, calculated using the 3-D FDTD method. Taken from Baba and Rakov [14]. (b) Same as (a) but calculated using the 2-D FDTD method and Agrawal coupling model, examined in this paper.

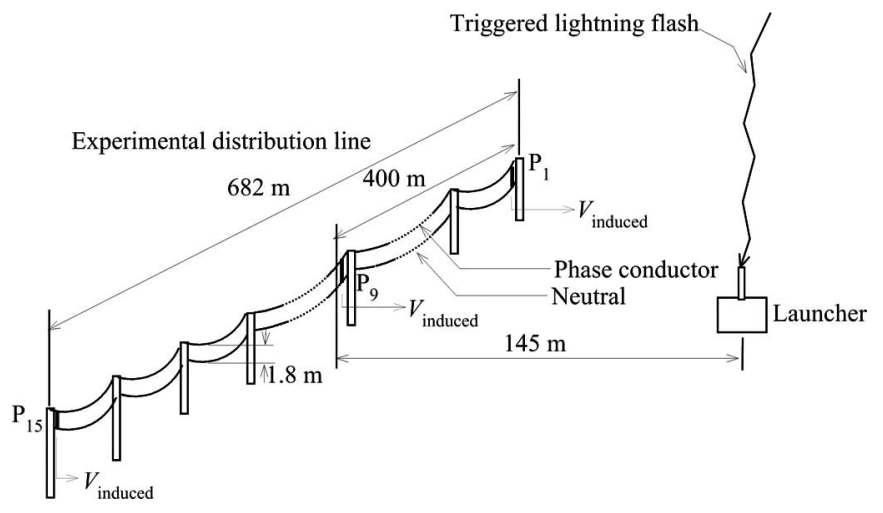

Fig. 5. Experimental configuration. Adapted from Barker et al. [23].

of two Heidler functions [24]

$$
\begin{aligned}
I(0, t) & =\frac{I_{0}}{\eta} \frac{\left(t / \tau_{1}\right)^{m}}{\left(t / \tau_{1}\right)^{m}+1} \exp \left(-\frac{t}{\tau_{2}}\right) \\
\eta & =\exp \left[-\left(\tau_{1} / \tau_{2}\right)\left(m \tau_{2} / \tau_{1}\right)^{(1 / m)}\right] .
\end{aligned}
$$

We used the following values of Heidler function parameters: $I_{01}=13.1 \mathrm{kA}, \tau_{11}=0.22 \mu \mathrm{s}, \tau_{12}=88 \mu \mathrm{s}, m_{1}=2, \eta_{1}=0.93$ for the first function, and $I_{02}=8.7 \mathrm{kA}, \tau_{21}=0.21 \mu \mathrm{s}, \tau_{22}=$ $61 \mu \mathrm{s}, m_{2}=2, \eta_{2}=0.92$ for the second function. The mea-

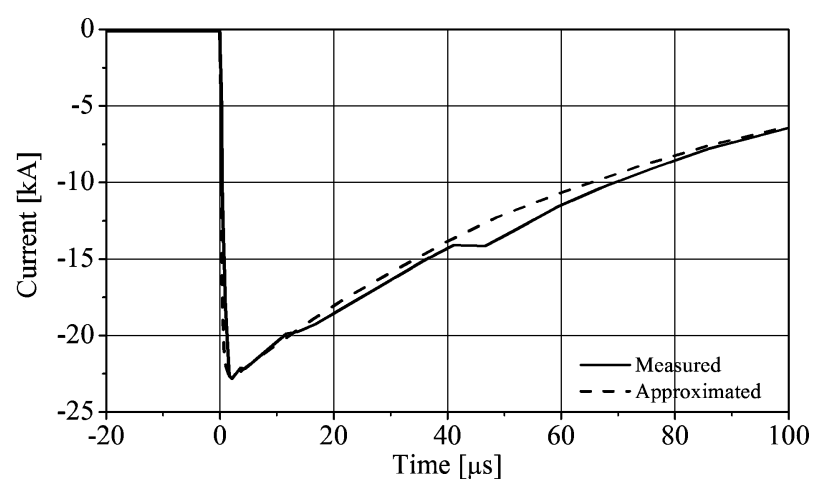

Fig. 6. Comparison of measured return-stroke current for Flash 93-05 and its approximation by two Heidler functions.

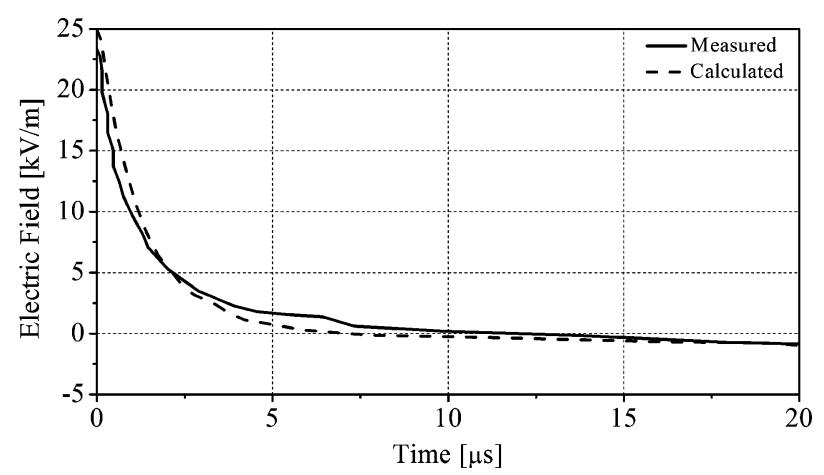

Fig. 7. Comparison of measured and calculated vertical electric field (returnstroke only) at $110 \mathrm{~m}$ for Flash 93-05. In the simulation, the MTLL model was employed.

sured return-stroke current (Flash 93-05) and its approximation by two Heidler functions are shown in Fig. 6 .

Measured and calculated vertical electric fields (return-stroke only) at a distance of $110 \mathrm{~m}$ from the lightning channel are shown in Fig. 7.

In our simulations, we varied the ground conductivity, lightning return-stroke speed, lightning return-stroke model, and grounding resistance value (the same for all three grounds) to examine their influence on the computed induced voltage at pole 9 (at the center of the line).

The simulation results are shown in Fig. 8, where one can see that the ground conductivity plays the most important role in determining the magnitude of induced voltages. The return-stroke speed has also some influence. As to the three return-stroke models (TL, MTLL, and MTLE) and the three grounding resistance values selected for the simulation, they do not seem to have much influence on the calculated results. The match between the simulation results and the experimental data is the best when the ground conductivity $\sigma_{g}=3.5 \times 10^{-3} \mathrm{~S} / \mathrm{m}$ and the lightning return-stroke speed $v=1.3 \times 10^{8} \mathrm{~m} / \mathrm{s}$. While our model reproduces measured voltages at pole 9 (at the center of the line) reasonably well, model-predicted voltages at pole 1 differ significantly from measured ones. Differences could be due to model assumptions and uncertainties in the line terminations. 


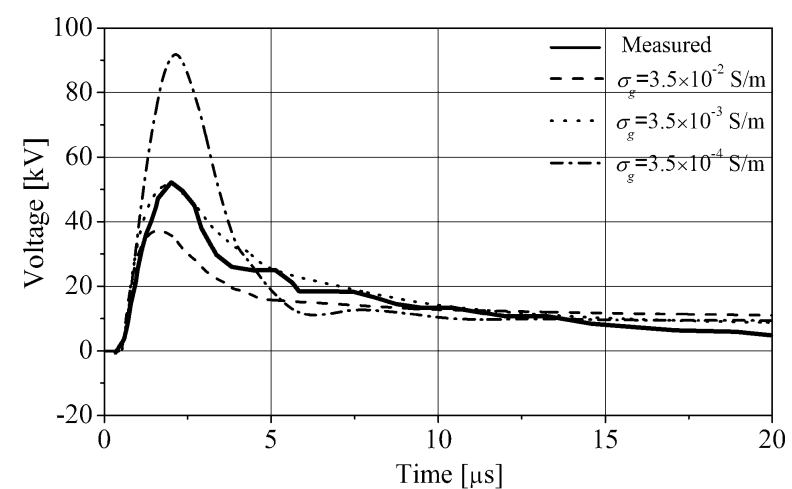

(a)

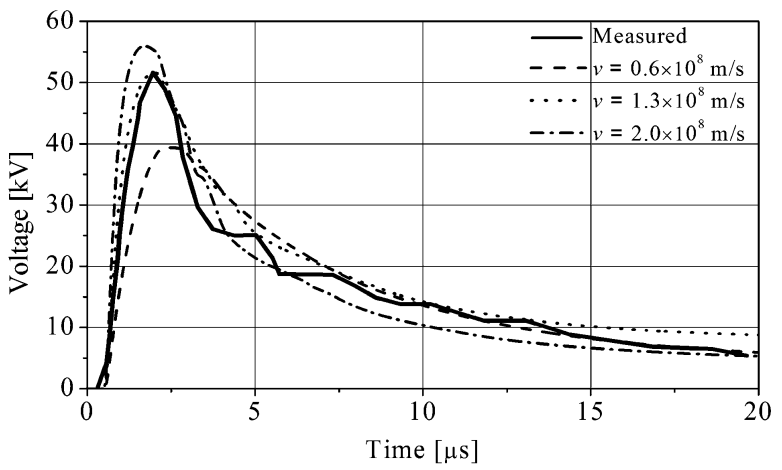

(b)

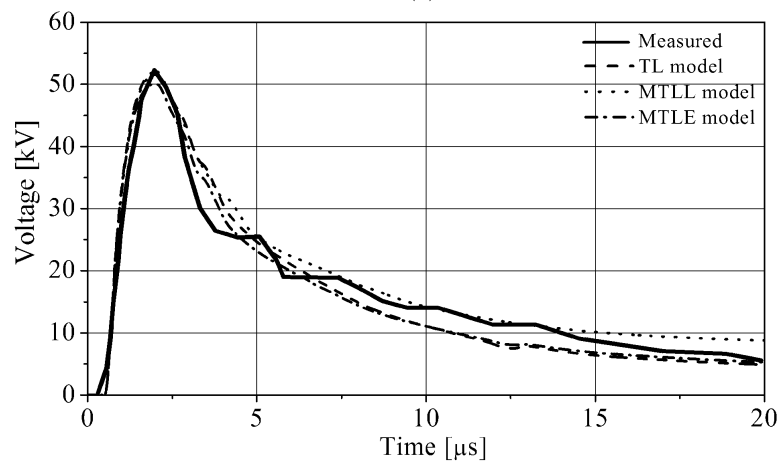

(c)

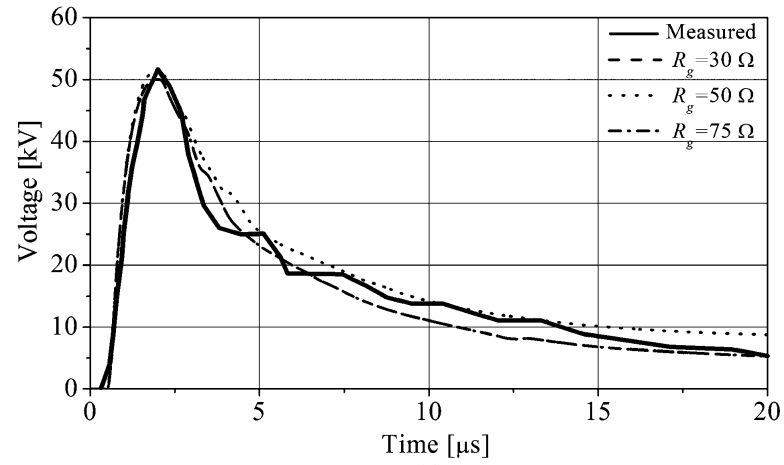

(d)

Fig. 8. Measured and calculated voltages at pole 9 for Flash 93-05. (a) Lightning return-stroke speed $v=1.3 \times 10^{8} \mathrm{~m} / \mathrm{s}$, grounding resistance $R_{g}=50 \Omega$, and ground conductivity $\sigma_{g}$ is varied. (b) Ground conductivity $\sigma_{g}=3.5 \times$ $10^{-3} \mathrm{~S} / \mathrm{m}$, grounding resistance $R_{g}=50 \Omega$, and the return-stroke speed is varied. (c) Ground conductivity $\sigma_{g}=3.5 \times 10^{-3} \mathrm{~S} / \mathrm{m}$, lightning returnstroke speed $v=1.3 \times 10^{8} \mathrm{~m} / \mathrm{s}$, grounding resistance $R_{g}=50 \Omega$, and returnstroke model is varied. (d) Ground conductivity $\sigma_{g}=3.5 \times 10^{-3} \mathrm{~S} / \mathrm{m}$, lightning return-stroke speed $v=1.3 \times 10^{8} \mathrm{~m} / \mathrm{s}$, and grounding resistance is varied. In (a), (b), and (d), the TL model was employed.

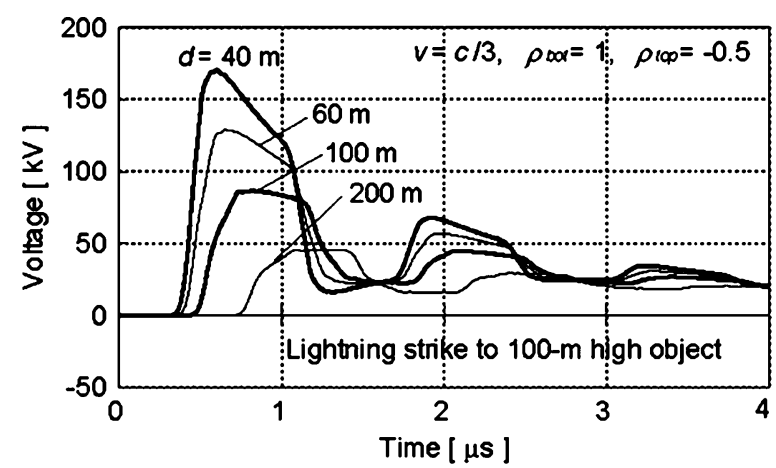

(a)

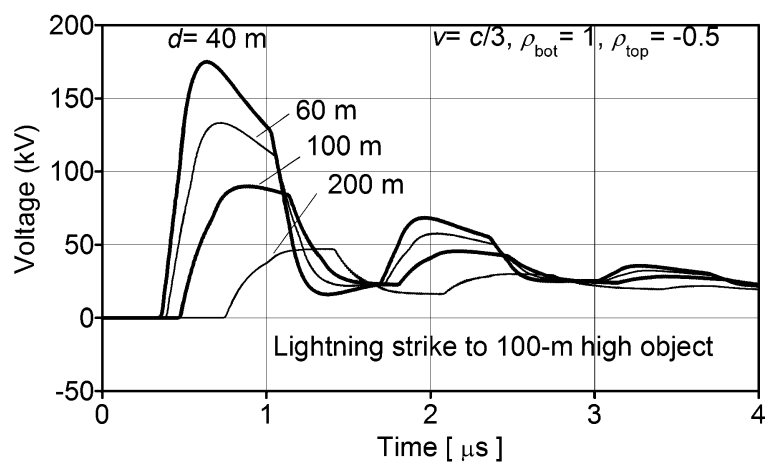

(b)

Fig. 9. (a) Lightning-induced voltages at the center point of a horizontal wire at distances $d=40,60,100$, and $200 \mathrm{~m}$ from the lightning channel, calculated using the 3-D FDTD method. Taken from Baba and Rakov [14]. (b) Same as (a) but calculated using the 2-D FDTD method and Agrawal coupling model.

\section{B. Lightning Strikes to Tall Grounded Objects}

1) Comparison With Voltages Computed Using the 3-D FDTD Method: In this section, we consider lightning strikes to a tall grounded object. The height of the strike object $h=$ $100 \mathrm{~m}$. The current reflection coefficient at the bottom of the object was set to $\rho_{\text {bot }}=1$ and the current reflection coefficient at the top of the object for upward propagating waves to $\rho_{\text {top }}=-0.5$. Other than that, the configuration is the same as that introduced in Section III-A1.

We compare our calculated induced voltages with those of Baba and Rakov [14] obtained using the 3-D FDTD method in Fig. 9. It can be seen that the calculated results obtained using these two different approaches agree well.

2) Comparison With Experimental Data: Michishita et al. [25] have carried out induced-voltage experiments on the coast of the Sea of Japan from 1993 to 1997. The plan view of the experimental site is shown in Fig. 10. The height of the lightning strike object was $200 \mathrm{~m}$. A horizontal wire $2.5 \mathrm{~mm}$ in radius and about $300 \mathrm{~m}$ in length was stretched $11 \mathrm{~m}$ above the ground. Both ends of this horizontal wire were terminated in $400-\Omega$ resistors. The distance from the close end of the line to the strike object was $373 \mathrm{~m}$. Waveforms of lightning current at the top of the strike object and lightning-induced voltages at both ends of the horizontal wire were measured.

Here, we compare simulation results for Michishita et al.'s configuration obtained using the 2-D FDTD method and the 


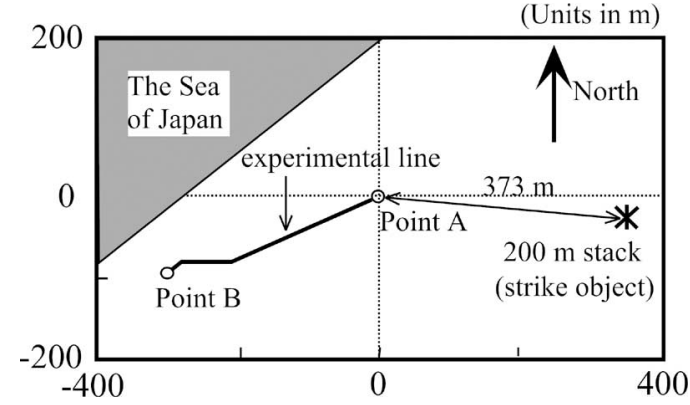

Fig. 10. Plan view of the experimental site. Adapted from Michishita et al. [25].

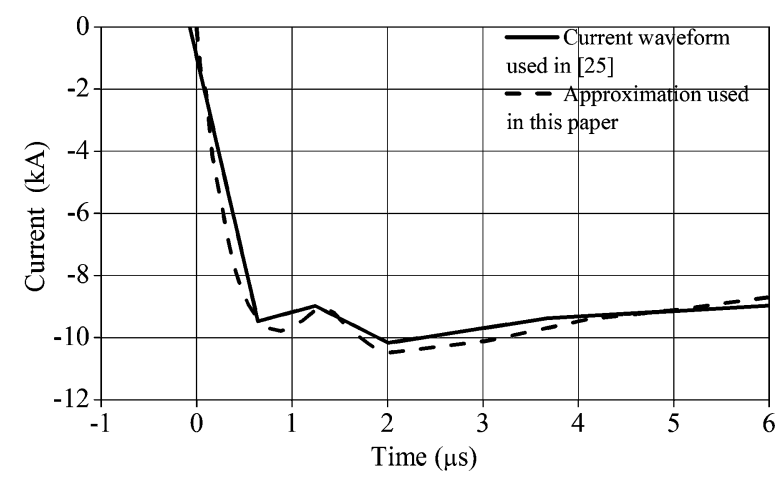

Fig. 11. Current waveform used in [25] and its approximation used in this paper.

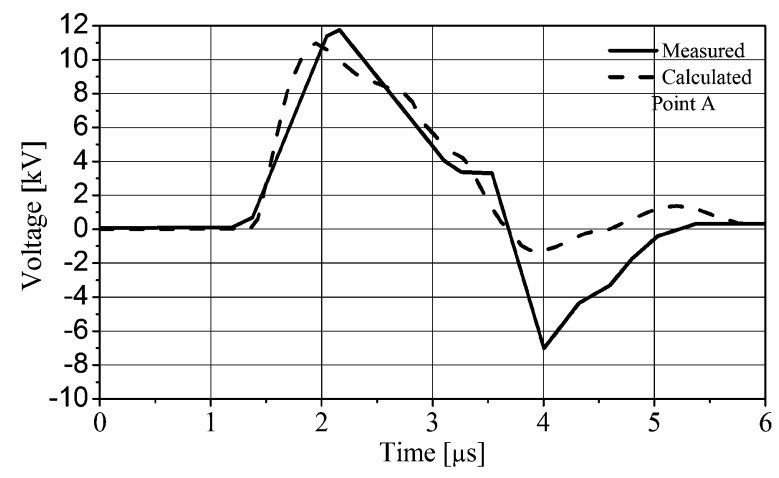

(a)

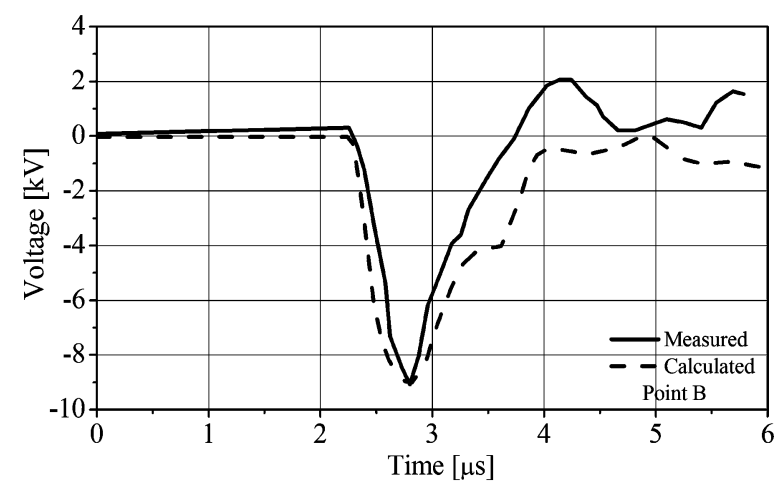

(b)

Fig. 12. Comparison of calculated induced-voltage waveforms with experimental data at the termination points. (a) At point A. (b) At point B (see Fig. 10).
Agrawal coupling model with measurements. Fig. 11 shows the current waveform used by Michishita et al. and its approximation used in our simulation. We assumed that the lightning return-stroke speed $v=1.0 \times 10^{8} \mathrm{~m} / \mathrm{s}$, and the conductivity and relative permittivity of ground $\sigma_{g}=0.01 \mathrm{~S} / \mathrm{m}$ and $\varepsilon_{r g}=10$, respectively. Following Michishita et al., we set $\rho_{\text {top }}=-0.6$, $\rho_{\text {bot }}=0.42$. Measured and computed induced-voltage waveforms at line terminations (points $\mathrm{A}$ and B) are compared in Fig. 12. It is clear from Fig. 12 that induced voltages calculated using the 2-D FDTD method and Agrawal coupling model are in fairly good agreement with the measured ones. Somewhat larger differences at point A might be due to the fact that the grounding resistance is not equal to the characteristic impedance of the overhead line in the experiment, while in the simulation, the grounding resistance is set to be equal to the characteristic impedance of the overhead line in order to avoid reflections at the terminals.

\section{SUMMARY}

We examined the 2-D FDTD method combined with the Agrawal electromagnetic coupling model for calculation of lightning-induced voltages on a single or multiconductor overhead line over lossy ground without employing the CoorayRubinstein formula. This approach generally provides sufficiently accurate results, while it greatly reduces the memory requirements and computation time as compared to the 3-D FDTD method. Specifically, it can save nearly half of the storage space and needs only a few minutes to obtain the final result. From the analysis carried out in this paper, it can be seen that induced voltages appear to be strongly dependent on ground conductivity, somewhat influenced by return-stroke speed, and essentially independent of return-stroke model (TL, MTLL, or MTLE).

\section{ACKNOWLEDGMENT}

The authors would like to thank Dr. Y. Baba, Dr. W. Radasky, and three anonymous reviewers for their helpful comments on this paper.

\section{REFERENCES}

[1] S. Rusck, "Induced lightning overvoltages on power transmission lines with special reference to the over-voltage protection of low voltage networks," Trans. R. Inst. Technol., Stockholm, Sweden, no. 120, 1958, pp. $1-118$.

[2] C. D. Taylor, R. S. Satterwhite, and C. W. Harrison, "The response of a terminated two-wire transmission line excited by nonuniform electromagnetic field," IEEE Trans. Antennas Propag., vol. AP-13, no. 6, pp. 987989, Nov. 1965.

[3] P. Chowdhuri and E. T. B. Gross, "Voltage surges induced on overhead lines by lightning strokes," Proc. Inst. Electr. Eng., vol. 114, no. 12, pp. 1899-1907, Dec. 1967.

[4] A. K. Agrawal, H. J. Price, and S. H. Gurbaxani, "Transient response of multiconductor transmission lines excited by a nonuniform electromagnetic field," IEEE Trans. Electromagn. Compat., vol. EMC-22, no. 3, pp. 119-129, May 1980

[5] F. Rachidi, "Formulation of the field-to-transmission line coupling equations in terms of magnetic excitation fields," IEEE Trans. Electromagn. Compat., vol. 35, no. 3, pp. 404-407, Aug. 1990.

[6] V. Cooray and V. Scuka, "Lightning-induced overvoltages in power lines: Validity of various approximations made in overvoltage calculations," 
IEEE Trans. Electromagn. Compat., vol. 40, no. 4, pp. 355-363, Nov. 1998.

[7] F. Rachidi, C. A. Nucci, and M. Ianoz, "Influence of a lossy ground on lightning-induced voltages on overhead lines," IEEE Trans. Electromagn. Compat., vol. 38, no. 3, pp. 250-264, Aug. 1996.

[8] V. Cooray, "Some considerations on the 'Cooray-Rubinstein' approximation used in deriving the horizontal electric field over finitely conducting ground," IEEE Trans. Electromagn. Compat., vol. 44, no. 4, pp. 560-565, Nov. 2002.

[9] V. Cooray, "Horizontal electric fields generated by return strokes," Radio Sci., vol. 27, no. 4, pp. 529-537, Jul./Aug. 1992.

[10] M. Rubinstein, "An approximate formula for the calculation of the horizontal electric field from lightning at close, intermediate, and long range," IEEE Trans. Electromagn. Compat., vol. 38, no. 3, pp. 531-535, Aug. 1996.

[11] J. R. Wait, "Concerning the horizontal electric field of lightning," IEEE Trans. Electromagn. Compat., vol. 39, no. 2, p. 186, May 1997.

[12] A. Shoory, R. Moini, S. H. H. Sadeghi, and V. A. Rakov, "Analysis of lightning-radiated electromagnetic fields in the vicinity of lossy ground," IEEE Trans. Electromagn. Compat., vol. 47, no. 1, pp. 131-144, Feb. 2005.

[13] H. K. Hoidalen, "Analytical formulation of lightning-induced voltages on multiconductor overhead lines above lossy ground," IEEE Trans. Electromagn. Compat., vol. 45, no. 1, pp. 92-100, Feb. 2003.

[14] Y. Baba and V. A. Rakov, "Voltages induced on an overhead wire by lightning strikes to a nearby tall grounded object," IEEE Trans. Electromagn. Compat., vol. 48, no. 1, pp. 212-224, Feb. 2006.

[15] Y. Baba and V. A. Rakov, "Lightning electromagnetic environment in the presence of a tall grounded strike object," J. Geophys. Res., vol. 110, no. D9, D09108, May 2005.

[16] Y. Baba and V. A. Rakov, "On the use of lumped sources in lightning return stroke models," J. Geophys. Res., vol. 110, no. D3, D03101, Feb. 2005.

[17] M. A. Uman and D. K. Mclain, "Magnetic field of the lightning return stroke," J. Geophys. Res., vol. 74, pp. 6899-6910, 1969.

[18] V. A. Rakov and A. A. Dulzon, "Calculated electromagnetic fields of lightning return stroke," Tekh. Elektrodinam., no. 1, pp. 87-89, 1987.

[19] C. A. Nucci, C. Mazzetti, F. Rachidi, and M. Ianoz, "On lightning return stroke models for LEMP calculations," presented at the 19th Int. Conf. Lightning Protection, Graz, Austria, Apr. 1988.

[20] C. Yang and B. Zhou, "Calculation method of electromagnetic field very close to lightning," IEEE Trans. Electromagn. Compat., vol. 49, no. 1, pp. 133-141, Jan. 2004.

[21] G. Mur, "Absorbing boundary conditions for the finite-difference approximation of the time-domain electromagnetic field equations," IEEE Trans. Electromagn. Compat., vol. EMC-23, no. 4, pp. 377-382, Nov. 1981.

[22] C. A. Nucci, G. Diendorfer, M. A. Uman, F. Rachidi, M. Ianoz, and C. Mazzetti, "Lightning return stroke current models with specified channel-base current: A review and comparison," J. Geophys. Res., vol. 95, no. D12, pp. 20 395-20 408, 1990.

[23] P. P. Barker, T. A. Short, A. R. Eybert-Berard, and J. P. Berlandis, "Induced voltage measurements on an experimental distribution line during nearby rocket triggered lightning flashes," IEEE Trans. Power Del., vol. 11, no. 2, pp. 980-995, Apr. 1996.

[24] F. Heidler, "Traveling current source model for LEMP calculation," in Proc. 6th Int. Symp. Tech. Exhib. Electromagn. Compat., Zurich, Switzerland, Mar. 1985, pp. 157-162.

[25] K. Michishita, M. Ishii, A. Asakawa, S. Yokoyama, and K. Kami, "Voltage induced on a test distribution line by negative winter lightning strokes to a tall structure," IEEE Trans. Electromagn. Compat., vol. 45, no. 1, pp. 135-140, Jan. 2003.

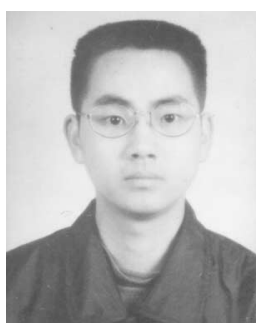

He-Ming Ren was born in Hunan, China, in April 1979. He received the B.E. and Ph.D. degrees from the Electromagnetic Pulse Laboratory, Nanjing Engineering Institute, Nanjing, China, in 2002 and 2007, both in electrical engineering.

$\mathrm{He}$ is currently a Lecturer in the College of Opotoelectric Science and Engineering, National University of Defense Technology, Changsha, China. His research interests include pulsed power technology and computational technology of lightning electromagnetic pulse.

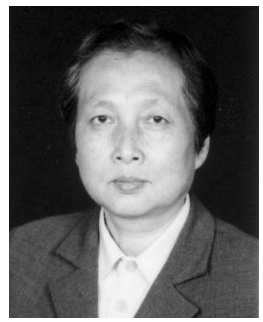

Bi-Hua Zhou (M'97) was born in Jiangsu, China, in 1940. She received the B.E. degree in radio communication engineering from the Beijing University of Posts and Telecommunications, Beijing, China, in 1965.

From 1988 to 1997, she was the Leader of the Electromagnetic Pulse Laboratory, Nanjing Engineering Institute, Nanjing, China, where she is currently a Professor. Her research interests include lightning, electromagnetic compatibility, and electromagnetic pulse protection.

Prof. Zhou was the recipient of three National Science and Technique Awards of China in 1993, 1995, and 2000, respectively.

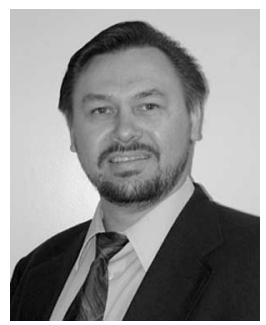

Vladimir A. Rakov (SM'96-F'03) received the M.S. and $\mathrm{Ph} . \mathrm{D}$. degrees in electrical engineering from Tomsk Polytechnical University (Tomsk Polytechnic), Tomsk, Russia, in 1977 and 1983, respectively.

From 1977 to 1979, he was an Assistant Professor of Electrical Engineering at Tomsk Polytechnic. During 1978, he was involved in lightning research at the High Voltage Research Institute (a division of Tomsk Polytechnic), where from 1984 to 1994, he was the Director of the Lightning Research Laboratory. He is currently a Professor in the Department of Electrical and Computer Engineering, University of Florida, Gainesville, where he is also the Co-Director of the International Center for Lightning Research and Testing. $\mathrm{He}$ is the author or coauthor of one book, more than 30 patents, and more than 400 papers and technical reports on various aspects of lightning, with more than 150 papers being published in reviewed journals.

Dr. Rakov is the Chairman of the Technical Committee on Lightning of the Biennial International Zurich Symposium on Electromagnetic Compatibility and former Chairman of the American Geophysical Union Committee on Atmospheric and Space Electricity. He is also a Fellow of the American Meteorological Society and the Institution of Electrical Engineers (presently the Institution of Engineering and Technology).

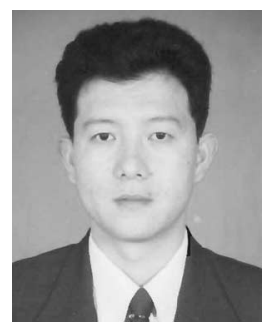

Li-Hua Shi (M'96) was born in Hebei, China, in 1969. He received the B.S. degree from Xidian University, Xi'an, China, in 1990, and the Ph.D. degree from Nanjing University of Aeronautics and Astronautics, Nanjing, China, in 1996, both in electrical engineering.

From 1997 to 1998 , he was a Postdoctoral Researcher at the Nanjing Engineering Institute, Nanjing, where he is currently a Professor in the Department of Electrical Engineering. He was a Visiting Scholar in Stanford University, Palo Alto, CA, for one year (2001). His current research interests include simulation and testing methods of electromagnetic pulses and time-frequency joint signal analysis.

Prof. Shi is a Senior Member of the Chinese Institute of Electronics.

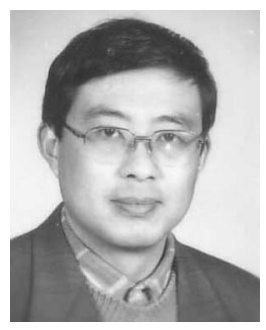

Cheng Gao (M'98) was born in Jiangsu, China, in 1964. He received the B.Eng. degree from the Naval Aeronautical Engineering Institute, Yantai, China, the M.Eng. degree from the Nanjing University of Aeronautics and Astronautics, Nanjing, China, and the Ph.D. degree from the Nanjing Engineering Institute, Nanjing, in 1985, 1994, and 2003, all in electrical engineering.

He is currently a Professor at the Nanjing Engineering Institute, Nanjing. His current research interests include electromagnetic compatibility and electromagnetic pulse protection

Dr. Gao received the Second Award for science and technology advances presented by the Chinese government in 2000 . 


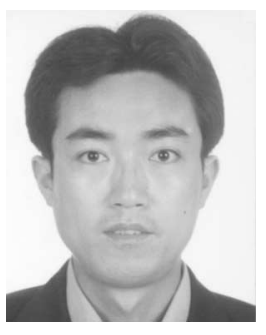

Jian-Hua Yang was born in Zhejiang, China, in March 1974. He received the B.Sc., M.Sc., and Ph.D. degrees from the National University of Defense Technology, Changsha, China, in 1996, 1999, and 2002, respectively.

$\mathrm{He}$ is currently an Associate Professor at the National University of Defense Technology. His current research interests include pulsed power, power conditioning technology, high-power repetitive switching, compact transformer, spiral pulse forming lines, stored energy medium, breakdown properties of liquids such as deionized water, pressured water, and ethylene glycol, high-power microwave focus, and slow-wave structure guilding on low-magnetic fields. 